\title{
Lung function, airway remodelling and inflammation in symptomatic infants: outcome at 3 years
}

\author{
Kristiina Malmström, ${ }^{1}$ Anna S Pelkonen, ${ }^{1}$ L Pekka Malmberg, ${ }^{1}$ Seppo Sarna, ${ }^{2}$ \\ Harry Lindahl, ${ }^{3}$ Merja Kajosaari, ${ }^{3}$ Markku Turpeinen, ${ }^{1}$ Sejal Saglani, ${ }^{4}$ Andy Bush, ${ }^{4}$ \\ Tari Haahtela, ${ }^{1}$ Peter K Jeffery, ${ }^{5}$ Mika J Mäkelä ${ }^{1}$
}

${ }^{1}$ Department of Allergy, Helsinki University Central Hospital Helsinki, Finland

${ }^{2}$ Department of Public Health, University of Helsinki, Finland

${ }^{3}$ Hospital for Children and Adolescents, Helsinki University Central Hospital, Helsinki, Finland

${ }^{4}$ Department of Respiratory Paediatrics, Imperial College London, UK

5 Lung Pathology, Department of Gene Therapy, Imperial College London, UK

\section{Correspondence to}

Kristiina Malmström,

Department of Allergy, Helsinki University Central Hospital; P 0 Box 160, Fl-00029 Helsinki, Finland;

kristiina.malmstrom@fimnet.fi

Received 23 March 2010 Accepted 11 November 2010 Published Online First

2 January 2011

\section{ABSTRACT}

Background Relationships between early deficits of lung function, infant airway pathology and outcome in symptomatic infants are unclear. A study was undertaken to determine the associations between early lung function, airway histology and inflammation in symptomatic infants with the continuance of respiratory symptoms, lung function and subsequent use of inhaled asthma medication at the age of 3 years.

Methods 53 children who underwent lung function measurements and bronchoscopy following referral to a specialist children's hospital for recurrent lower respiratory symptoms at a mean age of 1 year were followed up at 3 years of age. Assessments were made of respiratory symptoms during the previous year, lung function by oscillometry and atopy by skin prick testing. Individual data on the purchase of asthma medications were obtained from the Social Insurance Institution for the 12 months preceding the follow-up visit.

Results 50 children (94\%) were re-evaluated, of whom 40 had ongoing airway symptoms. 11/39 (28\%) who underwent successful oscillometry had reduced lung function, 31/50 (62\%) used inhaled corticosteroids (ICS) regularly and 12/50 (24\%) used ICS intermittently. Abnormal lung function at infancy was associated with ongoing airway symptoms $(p<0.001)$ and with the purchase of ICS $(p=0.009)$ and $\beta$ agonists $(p=0.002)$. Reticular basement membrane thickness in infancy and the numbers of mucosal mast cells, but not eosinophils, correlated significantly with the amount of ICS purchased at 3 years ( $p=0.003$ and $p=0.018$, respectively).

Conclusions Reduced lung function, thickening of the reticular basement membrane and increased density of mucosal mast cells in infancy are associated with respiratory morbidity and treatment needs at age 3 years in this highly selected group of children.

\section{INTRODUCTION}

Respiratory symptoms and wheeze are common during infancy. Clinical characteristics that affect the outcome include frequency of wheezing, history of eczema, peripheral blood eosinophilia, allergic rhinitis, wheezing without colds and parental history of asthma. ${ }^{1}$ An increased risk of wheeze during the first years of $\operatorname{life}^{2-5}$ and an increased risk of doctor-diagnosed asthma by 2 years ${ }^{6}$ have been associated with reduced lung function (LF) measured as early as at birth to 3 months of age in healthy children. In a recent birth cohort study of healthy infants, reduced LF at birth, measured by tidal breathing flow-volume loops, was associated with an increased risk of developing asthma and severe bronchial hyperresponsiveness by 10 years of age. ${ }^{7}$ Moreover, airway responsiveness in infancy is associated with persistence of symptoms later in childhood. ${ }^{8}$

Thickening of the bronchial epithelial reticular basement membrane (RBM) and bronchial eosinophilic inflammation are characteristic pathological findings in adult asthma, ${ }^{9}$ in school-aged children with severe asthma ${ }^{10-12}$ and in children of preschool age with severe recurrent wheeze. ${ }^{13}$ We have previously reported the airway pathology of steroid-naive infants with recurrent lower respiratory symptoms in terms of thickness of RBM, inflammatory cell counts and specific airway conductance by whole body plethysmography. A decrease in specific airway conductance was detected in $38 / 53$ infants $(72 \%)$, yet a significantly thickened RBM and tissue eosinophilia were not features of the group as a whole. ${ }^{14}$

In the present follow-up study of these infants we examined current airway symptoms, LF, atopy and the use of inhaled asthma medications at the age of 3 years. We tested for associations between these outcome parameters and infant symptoms, LF and our previous individual measures of RBM thickness and tissue eosinophilia.

\section{METHODS}

\section{Subjects and study design}

The children in the original study population were initially evaluated for their symptoms between October 2000 and September 2003. A total of 53 full-term Caucasian infants ( $>37$ weeks gestation) participated in the study. All children had been referred to a tertiary centre for investigation of recurrent lower respiratory symptoms including dyspnoea, cough and wheeze. As part of their clinical assessment, children underwent whole body plethysmography at the mean age of 1.0 year (range 0.28-2.16), after which bronchoscopy was performed. ${ }^{14}$ Functional residual capacity, specific airway conductance (sGaw) and bronchodilator responsiveness (BDR) were measured. Abnormal baseline LF was defined as sGaw below the fifth centile (Z-score $<-1.65$ ) of the reference range, which was based on reference data obtained with similar equipment. ${ }^{15}$ BDR was diagnosed if sGaw increased by $>30 \%$ and at least 2 SDs of baseline variation after $0.6 \mathrm{mg}$ salbutamol via Nebunette (AstraZeneca, Sweden). The infants were grouped according to LF as follows: Group A $(n=16)$, decreased sGaw with BDR; Group B $(n=22)$, decreased sGaw without BDR; and Group C 
$(\mathrm{n}=15)$, normal sGaw. The term 'reduced infant LF' is used for groups $\mathrm{A}$ and/or B. Exclusion criteria were use of corticosteroids within 8 weeks of the LF visit; small for gestational age; height at the time of investigation $<2.5 \mathrm{SD}$; respiratory distress syndrome; bronchopulmonary dysplasia; respiratory infection in the 14 days preceding lung function; severe atopic dermatitis; obvious bronchomalacia or other structural defect; sGaw $<35 \%$ of predicted.

Endobronchial biopsies taken from biopsy samples from the main carina were analysed for RBM thickness, determined by light microscopy, and for counts of subepithelial inflammatory cells (eosinophils, neutrophils, mast cells, plasma cells, lymphomononuclear cells) identified by their ultrastructure using transmission electron microscopy. ${ }^{14}$ The paediatricians treating the children were blinded to the individual RBM and inflammatory cell count data.

At 3 years of age the children were invited to a follow-up visit including LF measurement by oscillometry ${ }^{16}$ and skin prick test. The visits were conducted between January 2003 and October 2005. The child's parent or guardian filled in a standardised questionnaire on airway symptoms and use of inhaled asthma medication. Children with recurrent wheezing, coughing or dyspnoea during the previous year were classified as having ongoing airway symptoms. Use of inhaled corticosteroids (ICS) during the previous year was categorised as regular (daily) or intermittent. Current LF was considered abnormal if respiratory resistance was increased (Z-score $>+1.65 \mathrm{SD}$ ) or respiratory reactance reduced ( $Z$-score $<-1.65)$ compared with the heightadjusted predicted value. ${ }^{16}$ Atopy was defined by a positive skin prick test to food or aeroallergens. ${ }^{14}$

\section{Purchase of inhaled asthma medication}

Individual data on the purchase of asthma medication were collected from the central register of the Social Insurance Institution for 12 months preceding the follow-up visit. The total amounts of ICS and inhaled $\beta$-agonists purchased were calculated from the number of packages, doses per package and strength of the molecule. The ICS was calculated in 'mg budesonide' and, since the dose equivalence between fluticasone and budesonide is approximately $1: 2,{ }^{17} 18$ fluticasone mg were doubled to give the budesonide equivalence. The unit of inhaled $\beta$ agonists was determined as 'mg salbutamol' and terbutaline was considered to be $40 \%$ of salbutamol.

\section{Statistical analyses}

Normality was assessed with the Shapiro-Wilk test. The Mann-Whitney $U$ test was used for comparisons of the use and purchase of asthma medication, questionnaire data and LF results at age 3 years between patient groups. Groups A and B were pooled to represent infants with reduced LF. The associations between findings at infancy and at 3 years and the use of asthma medication during the third year of life were evaluated by the Spearman correlation test. The association in $2 \times 2$ tables was tested with the Fisher exact test. Two-sided $p$ values $<0.05$ were considered statistically significant. Statistical analyses were performed with SPSS Software for Windows Version 17.0.

\section{RESULTS}

The original cohort consisted of 53 infants of whom 50 children (94\%) completed follow-up at a median age of 3.1 years (range 2.8-3.7 years). The median time between the initial measurements and follow-up was 2.3 years (range $1.1-2.9$ years). LF measurement by oscillometry was conducted successfully in 39/ 50 children (78\%).

\section{Symptoms, LF, atopy and use and purchase of inhaled asthma medication at age 3 years}

Forty of the 50 infants (80\%) had ongoing airway symptoms (wheeze, cough or dyspnoea) and 21 (42\%) had ongoing wheeze

Table 1 Outcome at age 3 years according to lung function at infancy $(n=50)$

\begin{tabular}{|c|c|c|c|c|}
\hline & Abnormal* LF & Normal LF & & \\
\hline & $(n=37)$ & $(n=13)$ & p Value $\dagger$ & \\
\hline Median (range) age (years) & $3.1(2.8-3.6)$ & $3.1(3.0-3.7)$ & 0.490 & Mann-Whitney U test \\
\hline Parental smoking & $13(35 \%)$ & $5(38 \%)$ & 0.933 & Fisher exact test \\
\hline Male & $25(68 \%)$ & $9(69 \%)$ & 0.912 & Fisher exact test \\
\hline Airway symptoms & & & & \\
\hline Ongoing wheeze & $18(49 \%)$ & $3(23 \%)$ & 0.191 & Fisher exact test \\
\hline Ongoing cough/dyspnoea & $18(49 \%)$ & $2(15 \%)$ & 0.05 & Fisher exact test \\
\hline Ongoing airway symptoms & $36(97 \%)$ & $4(31 \%)$ & $<0.001$ & Fisher exact test \\
\hline Reported use of ICS & $37(100 \%)$ & $6(46 \%)$ & $<0.001$ & Fisher exact test \\
\hline Regular & $27(73 \%)$ & $4(31 \%)$ & 0.018 & Fisher exact test \\
\hline Periodic & $10(27 \%)$ & $2(15 \%)$ & 0.480 & Fisher exact test \\
\hline Purchase of asthma medication & & & & \\
\hline Median (IOR) ICS (mg) & $60(80)$ & $0(40)$ & 0.009 & Mann-Whitney U test \\
\hline $\begin{array}{l}\text { Median (IOR) inhaled } \beta \\
\text { agonists (mg) }\end{array}$ & $40(120)$ & $0(40)$ & 0.002 & Mann-Whitney U test \\
\hline Skin prick test positive $(n=49)$ & $10(27 \%)$ & $6(46 \%)$ & 0.304 & Fisher exact test \\
\hline Oscillometry (N) & 29 & 10 & & \\
\hline Median (IOR) Rrs5 (kPa/l/s) & $1.2(0.21)$ & $1.26(0.32)$ & 0.357 & Mann-Whitney U test \\
\hline Median (IQR) Rrs5 (Z-score) & $0.43(1.11)$ & $0.64(1.32)$ & 0.217 & Mann-Whitney U test \\
\hline Median (IOR) Xrs5 (kPa/l/s) & $-0.40(0.17)$ & $-0.42(0.17)$ & 0.384 & Mann-Whitney U test \\
\hline Median (IQR) Xrs5 (Z-score) & $-0.10(2.53)$ & $-0.54(1.90)$ & 0.335 & Mann-Whitney U test \\
\hline Abnormal LF§ at 3 years & $8 / 29(28 \%)$ & $3 / 10(30 \%)$ & 1.0 & Fisher exact test \\
\hline
\end{tabular}

Bold denotes $\mathrm{p}<0.05$

*Abnormal LF in infancy defined as reduced LF (specific airway conductance sGaw Z-score $<-1.65$ ).

†Fisher exact test for dichotomous variables and Mann-Whitney $U$ test for continuous variables. The comparisons are between abnormal and normal LF; $p$ values are not corrected for multiple comparison.

$\ddagger$ Purchase of asthma medication during third year of life.

$\S$ Abnormal LF at 3 years of age defined as Rrs5 $>1.65 \mathrm{SD}$ of predicted or Xrs5 $<1.65 \mathrm{SD}$.

ICS, inhaled corticosteroids; LF, lung function; Rrs5, respiratory resistance; Xrs5, respiratory reactance. 
Table 2 Spearman correlations between findings and symptoms at 3 years of age and the purchase of asthma medication $(n=50)$

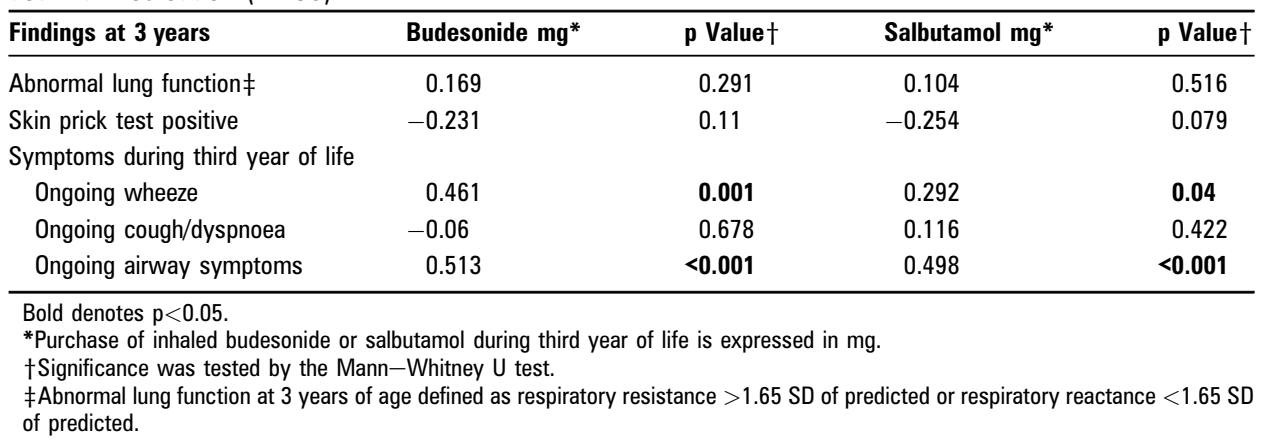

at 3 years of age. The symptoms became milder in 43 children $(86 \%)$ and worse in only one child (2\%) according to the questionnaire. Twenty-two children (44\%) experienced these airway symptoms without upper respiratory viral infection. The outcome at 3 years of age is shown in table 1.

Oscillometry was performed successfully in 39/50 children (78\%) and current LF was normal in 28/39 (72\%). Atopy was present in 16/49 children (33\%) at age 3 years. Atopic status was unchanged in $35 / 49$ children (71\%), in six children sensitisation had developed and in eight children sensitisation had disappeared compared with that at median age of 1 year. ${ }^{14}$ There was no association between atopic status in infancy and symptoms, LF, reported or purchased use of asthma medication at 3 years of age.

The parents or guardians for $31(62 \%)$ and 12 (24\%) of the 50 children respectively reported continuous and intermittent use of ICS during the previous year (table 1). In all, any use of ICS was reported for $43 / 50$ (86\%). Purchase of ICS according to data collected from the central register of the Social Insurance Institution was registered for $39 / 50$ children (78\%) during the previous year: budesonide for $37 / 50$ (74\%), fluticasone for $7 / 50$ $(14 \%)$ and both for $5 / 50$. The purchased inhaled medications are shown in $\mathrm{mg}$ in table 1.

There was no association between either abnormal LF at the age of 3 years or atopy at the age of 3 years and the purchase of asthma medication. The continuance of airway symptoms (wheeze, cough or dyspnoea) and the continuance of wheeze alone at the age of 3 years were significantly associated with purchased amounts of ICS ( $p<0.001$ and $p=0.001$, respectively) and inhaled $\beta$ agonists $(\mathrm{p}<0.001$ and $\mathrm{p}=0.04$, respectively) during the third year of life (table 2).

\section{Association with reduced LF at infancy}

Only reduced infant LF, but not BDR, was associated with any of the outcome parameters so the comparisons made here are between Groups A+B together and Group C (normal LF) (table 1). Reduced LF at infancy was associated with ongoing airway symptoms at 3 years of age $(p<0.001$, Fisher exact test) but not with ongoing wheeze alone ( $p=0.191$, Fisher exact test). In addition, reduced LF at infancy was significantly associated with regular use of ICS reported by parents $(\mathrm{p}=0.018$, Fisher exact test) and with the purchased amount of ICS $(p=0.009$; Mann-Whitney $U$ test) and inhaled $\beta$ agonists ( $p=0.002$, Mann-Whitney $U$ test) during third year of life (tables 1 and 3 and figure 1). Significant associations were not found between LF values at infancy and those determined at 3 years of age.

\section{Association with airway pathology at infancy}

We had already obtained endobronchial biopsies from these children at infancy during clinical bronchoscopy for severe wheeze and/or cough. While, as a group, epithelial RBM was not significantly thickened, the various individual values in infancy correlated significantly ( $r=0.406, p=0.003$; Spearman test) with the amount of purchased ICS but not with reported regular $(\mathrm{r}=0.220, \mathrm{p}=0.125$; Spearman test) or intermittent $(\mathrm{r}=-0.309$, $p=0.029$; Spearman test) use of ICS at 3 years. Moreover, the number of mast cells (but not eosinophils) in the biopsies correlated significantly ( $r=0.378, p=0.018$; Spearman test $)$ with the amount of purchased ICS (table 3 ). No association was detected between the individual thickness of RBM or counts of inflammatory cells at age 1 year and LF at 3 years.

Table 3 Infant correlation for purchase of asthma medication at age of 3 years for 50 children

\begin{tabular}{|c|c|c|c|c|c|}
\hline & \multicolumn{2}{|c|}{ Budesonide (mg)* } & \multicolumn{2}{|c|}{ Salbutamol (mg)* } & \\
\hline & Correlation & p Value $\dagger$ & Correlation & p Value $\dagger$ & \\
\hline \multicolumn{6}{|l|}{ Infant lung function } \\
\hline Abnormalf & 0.375 & 0.007 & 0.445 & 0.001 & Mann-Whitney U test \\
\hline sGaw (Z-score) & -0.168 & 0.243 & -0.170 & 0.239 & Spearman test \\
\hline FRC (Z-score) & 0.026 & 0.856 & 0.137 & 0.343 & Spearman test \\
\hline Infant skin prick test positive & -0.051 & 0.727 & -0.107 & 0.461 & Mann-Whitney U test \\
\hline \multicolumn{6}{|l|}{ Infant bronchial biopsy } \\
\hline RBM (mm) & 0.406 & 0.003 & 0.201 & 0.162 & Spearman test \\
\hline Mast cells & 0.378 & 0.018 & 0.228 & 0.163 & Spearman test \\
\hline \multicolumn{6}{|l|}{ Symptoms during infancy } \\
\hline Frequent wheeze & 0.300 & 0.034 & 0.121 & 0.402 & Mann-Whitney U test \\
\hline Wheeze between colds & 0.102 & 0.482 & 0.125 & 0.388 & Mann-Whitney U test \\
\hline
\end{tabular}


A

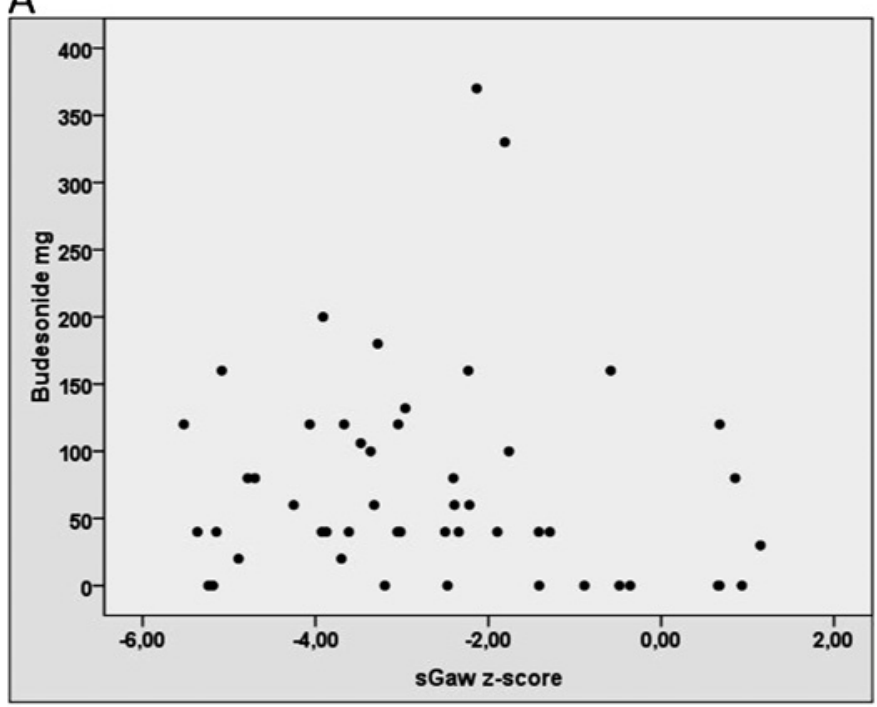

C

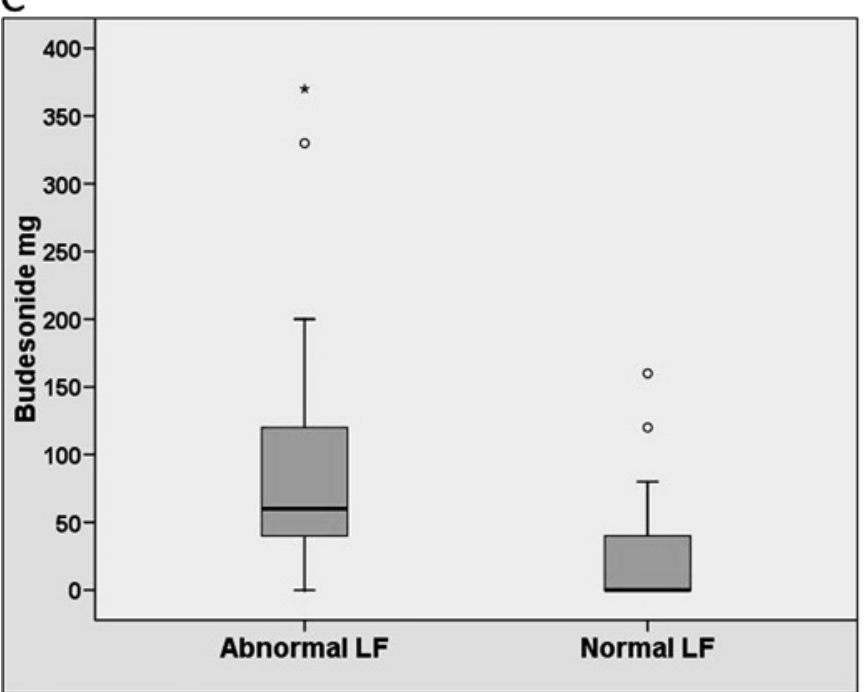

B

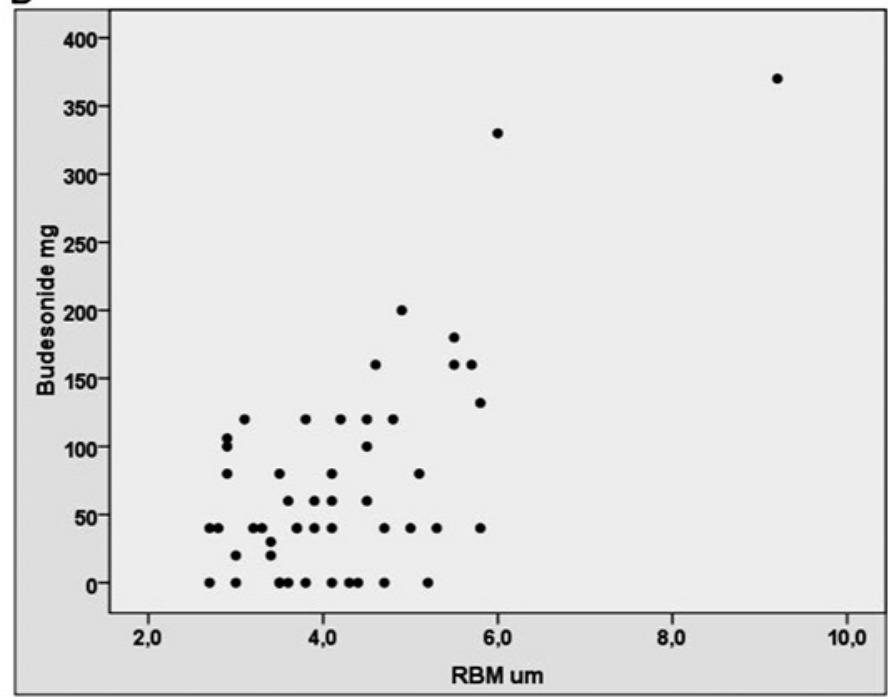

D

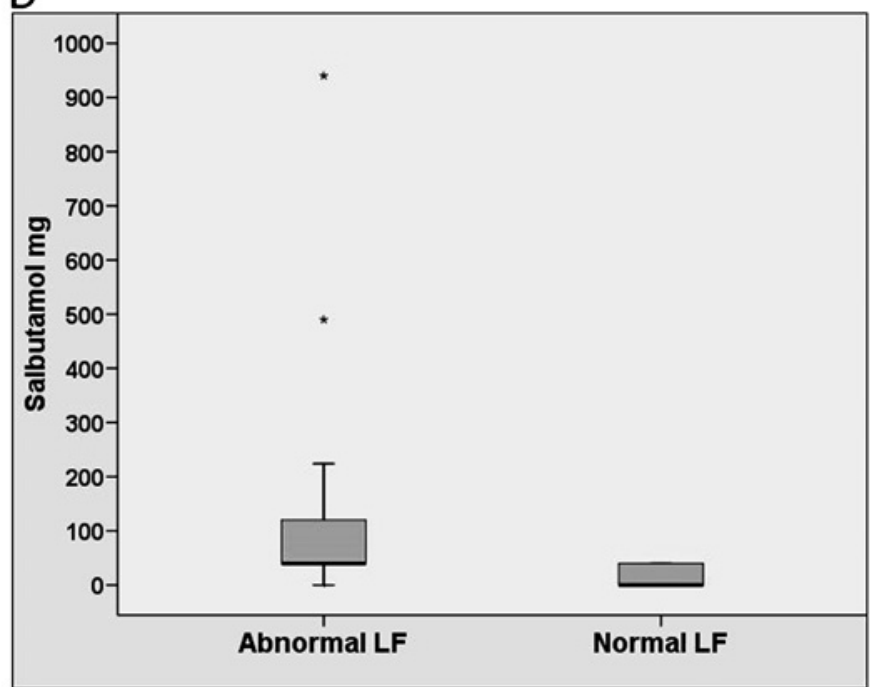

Figure 1 (A) Correlation between purchase of budesonide (in $\mathrm{mg}$ ) and lung function (LF) expressed as sGaw Z-score ( $r=-0.168, p=0.243$; Spearman test). Abnormal LF is considered if the sGaw Z-score is $<-1.6$. (B) Correlation between purchase of budesonide (in mg) and reticular basement membrane (RBM) membrane (in $\mu \mathrm{m})(r=0.406, p=0.003$; Spearman test). Purchase of (C) inhaled budesonide and (D) salbutamol (in mg) during the third year of life is significantly higher in infants with abnormal LF than in those with normal LF ( $p=0.009$ and $p=0.02$, respectively; Mann-Whitney U test).

\section{DISCUSSION}

This follow-up study shows that reduced LF in infants with recurrent lower respiratory symptoms is significantly associated with ongoing airway symptoms, regular use of asthma medication and larger purchased amounts of ICS and inhaled $\beta$ agonists at the age of 3 years. Moreover, the results suggest that the individual values of RBM thickness and mucosal mast cell density in infancy correlate with later more frequent use of asthma medication.

We have learnt from birth cohort studies that most cases of persistent wheeze and asthma begin in early childhood, ${ }^{19}$ often in association with reduced infant LF. ${ }^{40}$ In the Norwegian birth cohort study, reduced LF at birth was associated with an increased risk of asthma by 10 years of age. ${ }^{7}$ In two other birth cohort studies, early reduced LF was consistently lower throughout childhood and adolescence into adulthood among those with persistent asthma and reduced LF in adulthood. ${ }^{21} 22$ We acknowledge that our study was of highly selected infants referred for investigation of severe symptoms to a specialist centre and not a birth cohort study, but the findings that reduced infant LF is associated with ongoing airway symptoms, with regular use of asthma medication and with larger purchased amounts of ICS and inhaled $\beta$ agonists at age of 3 years are, nevertheless, in accord with the cohort studies. However, airway symptoms at 3 years of age are often transient and we do not suggest that the present results can be extrapolated to asthma at an older age.

In the present study the LF techniques used were different at baseline and follow-up owing to the differing age of children at the times of assessment. The results of whole body plethysmography and the oscillometric technique cannot be compared directly but have been shown to correlate with each other. ${ }^{23}$ Oscillometry measures total respiratory resistance while body plethysmography measures direct airway resistance. Methodspecific reference values and Z-scores were used to evaluate the LF deficit at the two time points of assessment. ${ }^{15} 24$ However, by 
3 years of age LF was normal in most children, which may be a consequence of spontaneous recovery of the airways, the result of treatment or the relatively low sensitivity of the lung function tests available to us.

BDR assessed at infancy was not significantly associated with ongoing airway symptoms, the use of inhaled medications or LF at 3 years, therefore the original infant groups with reduced LF with or without BDR were combined in the present study analyses. Previous studies on BDR in infants have been contradictory. Infants with recurrent wheeze have been shown to respond to inhaled salbutamol, assessed by decrease in sGaw, ${ }^{25}$ and in one study BDR was associated with known risk factors of asthma. ${ }^{26}$ However, the physiological mechanisms associated with BDR at infancy are probably different from that in older subjects with asthma. Our results do not support the concept that BDR at infancy would be predictive of later respiratory morbidity.

In an observational non-interventional cohort study from Norway $^{27}$ the improvement in LF increased with increasing reported duration of ICS treatment in a group of very young children with recurrent bronchial obstruction and reduced LF at presentation. In accordance with this report, our study demonstrated a significant correlation between abnormal infant LF and reported regular use of ICS during the third year of life. Since reported use may be different from actual use, we wanted also to analyse the amount of purchased drugs on the assumption that families use the purchased drugs to treat their children. These data are automatically registered in Finland from pharmacies to the central register of the Social Insurance Institution. The purchase data confirmed the reported data on the regular use of ICS given by parents, and a significant correlation was seen between the amount of drug purchased and abnormal infant LF. This highlights the importance of early abnormal LF in determining the likelihood of subsequent continuance of airway symptoms. Although ICS treatment may not modify the course of the condition, it has been shown at least to control the symptoms of asthma. ${ }^{28}$ Patients with the worst symptoms may therefore have used ICS more regularly in the present study, explaining the association between impaired infant LF and a larger purchased amount of ICS later in life.

The RBM is known to be thickened in children of school age with severe asthma, a similar finding to that in adults with severe asthma. ${ }^{10-12}$ An association between thickening of the RBM and eosinophilic airway inflammation has recently been shown even in children of preschool age with recurrent wheeze. ${ }^{13}$ In the present infant cohort a significant correlation between infant RBM and subsequent purchase of ICS mg was found. Furthermore, we have shown for the first time that mucosal mast cell numbers at age 1 year predict the use of ICS at age 3 years. Owing to the rather small sample size and the number of variables to be tested, multiple comparison bias is possible. While further testing is required, these data support the hypothesis that mast cells may be important in the progression of respiratory symptoms in the young. In adult patients it has been shown that the presence of mast cells in airway smooth muscle is associated with increased airway responsiveness to methacholine in asthma, ${ }^{29}$ emphasising a clinically relevant role for mast cells in the pathology of asthma. In this respect it is interesting to note that there was one 10-month-old boy who had a clearly thickened RBM of $9.2 \mu \mathrm{m}$ and who also had the highest number of mast cells, as well as eosinophils. ${ }^{14}$ Now, at the age of 3 years he has continuing wheeze, frequent emergency visits and the highest purchased amount of both ICS and inhaled $\beta$ agonists of all those we studied. He probably represents a rare case of early onset atopic asthma, in our study $<2 \%$ of an already highly selected group.

Reduced LF may be related to mechanisms other than airway morphology. In a recent study using high-resolution CT, structural findings in airway walls were not related to lower forced expiratory flows in infants with recurrent wheeze, suggesting that reduced LF is associated with mechanisms other than thickened airway walls such as more collapsible airways or decreased pulmonary elastic recoil. ${ }^{30}$

Earlier studies that tried to target early wheezing by using ICS did not show obvious clinical benefit or diseasemodifying effect. ${ }^{28} 3132$ However, the children did not undergo pre-randomisation LF tests to find possible subgroups that might benefit from the early use of ICS.

One potential bias of this study is reverse causation. Employing extensive diagnostic measurements at infancy might have led to subsequent increased parental concern about symptoms and therefore a greater likelihood of later use of inhaled medication. However, we did see a correlation between RBM thickness and amount of medication purchased, suggesting that a significant part of the finding is attributable to biological differences.

In conclusion, reduced baseline LF in symptomatic infants is significantly associated with the continuance of lower airway symptoms and with the use and purchase of asthma medication at 3 years of age. Furthermore, both RBM thickness and the density of bronchial mucosal mast cells in infancy are associated with amount of purchased ICS at age 3 years. Early changes in airway pathology and LF may therefore have a role in subsequent respiratory morbidity.

Acknowledgements The authors thank nurses Tuija Rito and Helena Punkari for their skill and care with the infants.

Funding This study has received funding from the Nummela Sanatorium Foundation Liv och Hälsa Foundation, Pediatric Research Foundation, Helsinki University Central Hospital Research Fund, Sigrid Juselius Foundation and AstraZeneca Finland.

\section{Competing interests None.}

\section{Patient consent Obtained.}

Ethics approval This study was conducted with the approval of the ethics committee of the Helsinki University Central Hospital.

Provenance and peer review Not commissioned; externally peer reviewed.

\section{REFERENCES}

1. Castro-Rodriguez JA, Holberg CJ, Wright AL, et al. A clinical index to define risk of asthma in young children with recurrent wheezing. Am J Respir Crit Care Med 2000;162:1403-6.

2. Yuksel B, Greenough A, Griffin F, et al. Tidal breathing parameters in the first week of life and subsequent cough and wheeze. Thorax 1996;51:815-18.

3. Tager IB, Hanrahan JP, Tosteson TD, et al. Lung function, pre- and post-natal smoke exposure, and wheezing in the first year of life. Am Rev Respir Dis 1993; 147:811-17.

4. Martinez FD, Morgan WJ, Wright AL, et al. Diminished lung function as a predisposing factor for wheezing respiratory illness in infants. $N$ Engl J Med 1988;319:1112-17

5. Murray CS, Pipis SD, McArdle EC, et al. Lung function at one month of age as a risk factor for infant respiratory symptoms in a high risk population. Thorax 2002; 57:388-92

6. Young $\mathbf{S}$, Arnott J, OKeeffe PT, et al. The association between early life lung function and wheezing during the first 2 yrs of life. Eur Respir J 2000;15:151-7.

7. Håland G, Lodrup Carlsen $\mathrm{KC}$, Snadvik $L$, et al. Reduced lung function at birth and the risk of asthma at 10 years of age. N Engl J Med 2006;355:1682-9.

8. Turner SW, Young S, Goldblatt J, et al. Childhood asthma and increased airway responsiveness- a relationship that begins in infancy. Am J Respir Crit Care Med 2009;179:98-104.

9. Jeffery PK. Remodeling in asthma and chronic obstructive lung disease. Am J Respir Crit Care Med 2001;164:S28-38.

10. Jenkins HA, Cool C, Szefler SJ, et al. Histology of severe childhood asthma: a case series. Chest 2003;124:32-41. 
11. de Blick J, Tillie-Leblond I, Tonnel $A B$, et al. Difficult asthma in children: analysis of airway inflammation. J Allergy Clin Immunol 2004;113:94-100.

12. Payne DN, Rogers AV, Adelroth E, et al. Early thickening of the reticular basement membrane in children with difficult asthma. Am J Respir Crit Care Med 2003;167:78-82.

13. Saglani S, Payne DN, Zhu J, et al. Early detection of air wall remodeling and eosinophilic inflammation in preschool wheezers. Am J Respir Crit Care Med 2007:176:858-64.

14. Saglani S, Malmström K, Pelkonen AS, et al. Airway remodelling and inflammation in symptomatic infants with reversible airway obstruction. Am J Respir Crit Care Med 2005;171:722-7.

15. Kraemer R, Graf Bigler U, Casaulta Aebischer C, et al. Clinical and physiological improvement after inhalation of low-dose beclomethasone dipropionate and salbutamol in wheezy infants. Respiration 1997;64:342-9.

16. Malmberg LP, Pelkonen A, Poussa T, et al. Turpeinen. Determinants of respiratory system input impedance and bronchodilator response in healthy Finnish preschool children. Clin Physiol Funct Imaging 2002;22:64-71.

17. Ferguson AC, Spier S, Manjra A, et al. Efficacy and safety of high-dose inhaled steroids in children with asthma: a comparison of fluticasone propionate with budesonide. J Pediatr 1999;134:422-7.

18. Adams N, Lasserson TJ, Cates CJ, et al. Fluticasone versus beclomethasone or budesonide for chronic asthma in adults and children. Cochrane Database Syst Rev 2007;(4):CD002310.

19. Von Mutius E. Pediatric origins of adult lung disease. Thorax 2001:56:153-7.

20. Turner SW, Palmer LJ, Rye PJ, et al. Infants with flow limitation at 4 weeks: outcome at 6 and 11 years. Am J Respir Crit Care Med 2002;165:1294-8.

21. Sears MR, Greene JM, Willan AR, et al. A longitudinal, population-based cohort study of childhood asthma followed to adulthood. N Engl J Med 2003;349:1414-22.
22. Strachan DP, Griffiths JM, Johnston AD, et al. Ventilatory function in British adults after asthma or wheezing illness at ages $0-35$. Am J Respir Crit Care Med 1996;154:1629-35

23. Hellinckx J, Cauberghs $M$, De Boeck K, et al. Evaluation of impulse oscillation system: comparison with forced oscillation technique and body plethysmography. Eur Respir J 2001:18:564-70.

24. Malmberg P, Pelkonen A, Poussa T, et al. [Reference values of the oscillometric technique give support to asthma diagnostics in small children] (In Finnish). Duodecim 2001:117:1541-4.

25. Kraemer R, Frey U, Sommer CW, et al. Short-term effect of albuterol, delivered via a new auxiliary device, in wheezy infants. Am Rev Respir Dis 1991;144:347-51.

26. Lodrup-Carlsen KC, Pettersen M, Carlsen KH. Is bronchodilator response in 2-yr-old children associated with asthma risk factors? Pediatr Allergy Immunol 2004;15:323-30

27. Devulapalli CS, Haaland G, Pettersen M, et al. Effect of inhaled steroids on lung function in young children: a cohort study. Eur Respir J 2004;23:869-75.

28. Guilbert TW, Morgan WJ, Zeiger RS, et al. Long-term inhaled corticosteroids in presechool children at high risk for asthma. N Engl J Med 2006;354:1985-97.

29. Brightling CE, Bradding P, Symon FA, et al. Mast-cell infiltration of airway smooth muscle in asthma. N Engl J Med 2002:346:1699-705.

30. Llapur CJ, Martinez TM, Coates C, et al. Lung structure and function of infants with recurrent wheeze when asymptomatic. Eur Respir J 2009;33:107-12.

31. Bisgaard $\mathbf{H}$, Hermansen MN, Loland L, et al. Intermittent inhaled corticosteroids in infants with episodic wheezing. N Engl J Med 2006;354:1998-2005.

32. Murray CS, Woodcock A, Langley SJ, et al; IFWIN study team. Secondary prevention of asthma by the use of inhaled fluticasone propionate in wheezy infants (IFWIN): double-blind, randomized, controlled study. Lancet 2006;368:754-62.

\section{Thorax Online Archive}

Visit our Online Archive - available back to 1946. Subscribers may access the entire archive freely. Non-subscribers have free access to all articles prior to 2006. A simple one-time registration is required that grants access to all the free archive content, across all of our specialist titles. To view or to register visit thorax.bmj.com. 